\title{
A Case with Ankylosing Spondylitis Who Developed Hodgkin Lymphoma Following Etanercept Therapy
}

\author{
Raikan Buyukavcı', Fusun Sahin ${ }^{2}$, Beril Dogu ${ }^{3 *}$ and Banu Kuran ${ }^{3}$
}

${ }^{1}$ Dr Kemal Beyazit Physical Medicine Center, Kahramanmaraş, Turkey

${ }^{2}$ Department of Physical Medicine and Rehabilitation, Pamukkale University Faculty of Medicine, Denizli, Turkey

${ }^{3}$ Department of Physical Medicine and Rehabilitation, Sisli Hamidiye Etfal Education and Research Hospital, Istanbul, Turkey

\begin{abstract}
Ankylosing Spondylitis (AS) is a chronic, systemic, and inflammatory rheumatic disease affecting primarily axial skeleton. In cases non-responsive to classical therapeutic approaches, tumor necrosis factor- $\alpha$ (TNF- $\alpha$ ) antagonists have become new treatment alternatives. With anti-TNF drugs usage, rate of lymphoma development has increased especially in patients with rheumatoid arthritis. In this case-report, we report a patient with (AS) who presented with Hodgkin Lymphoma $(\mathrm{HL})$ at the $3^{\text {rd }}$ month of anti-TNF therapy. This complication should be remembered and close follow-up should be pursued in patients who are under immunosuppressive therapy with anti-TNF drugs, which were also used in the treatment of rheumatic diseases.
\end{abstract}

Keywords: Ankylosing spondylitis; Etanercept; Hodgkin lymphoma

\section{Introduction}

As an inflammatory rheumatic disease, the main clinical characteristics of Ankylosing Spondylitis (AS) are inflammatory low back pain secondary to sacroiliitis and spondylitis; some patients may also develop peripheral arthritis, enthesitis and acute anterior uveitis [1]. In cases with AS, pain, stiffness, physical limitations constitute the major symptoms of the disease and they adversely affect the quality of life [2]. Treatment modalities in AS are limited to physiotherapeutic modalities and Non-Steroidal Anti inflammatory Drugs (NSAIDs); moreover, Disease-Modifying Anti Rheumatic Drugs (DMARDs) are not effective in the treatment of the axial disease. However, all inhibitors of tumor necrosis factor- $\alpha$ (TNF- $\alpha$ ) have found a place in the management of AS as a novel and effective alternative. According to the recommendations of study groups of British Convention of Rheumatology (BCR) and Ankylosing Spondylitis Assessment Study Group (ASAS), anti-TNF therapy is indicated for patients with active disease who are refractory to standard therapy [3].

TNF- $\alpha$ is a proinflammatory cytokine which plays a role in the pathogenesis of AS and other forms of spondyloarthritis. Etanercept is a fusion protein with a p75 human TNF- $\alpha$ receptor and it is indicated in cases with Rheumatoid Arthritis (RA), AS and Psoriatic Arthritis (PSA) who are refractory to conventional therapies. Although antiTNF drugs are a treatment option in inflammatory arthritis, they possess some side effects and contraindications such as predisposition to infections, reactivation of tuberculosis, congestive heart failure, and malignancies [4,5]. Lymphoproliferative diseases, especially Non-Hodgkin Lymphoma (NHL), are observed at an increasing rate in immune deficient and immune suppressed patients. In patients with RA, the incidence of both Hodgkin Lymphoma (HL) and NHL increases irrespective of the drug used [6]. However, such an excess risk has as yet not been demonstrated in treatment of spondylarthrities, especially AS. We are presenting a case with HL that emerged during short term use of etanercept in a patient with AS, who was refractory to conventional treatments.

\section{Case}

A 39 year-old male patient presented with migratory pain, mostly localized at lumbar region. It was learned from patient history that he had not been able to work for 8 years because of his pain and had experienced 3 episodes of uveitis. He had been operated for a cyst localized on left inguinal region with unknown etiology. $\mathrm{He}$ also suffered nocturnal pain and morning stiffness lasting for 2 hours. He was a non-smoker. No family history remarkable for a rheumatic disease was present. Systemic examination of the patient who described an inflammatory low back pain was not remarkable. Results of locomotor system examination were as follows: unrestricted and painless movements of cervical joints, mildly limited lumbar extension; finger -ground distance: $3 \mathrm{~cm}$; hand-ground distance in modified lumbar Schober's test: $4 \mathrm{~cm}$; range of chest expansion: $2.5 \mathrm{~cm}$; hip movements were with normal range of motion (ROM); Flexion, Abduction and External Rotation (FABER) test elicited pain at sacroiliac joints. Other peripheral joint movements were unrestricted and painless. Laboratory test results were as follows: Erythrocyte Sedimentation Rate (ESR): $27 \mathrm{~mm} / \mathrm{h}$; C-reactive protein (CRP): $17.4 \mathrm{mg} / \mathrm{lt}$. His hemogram and biochemical tests apart from Alanine Transaminase (ALT) were within normal limits. ALT level was $57 \mathrm{IU} / \mathrm{lt}$ (normal range: 0-41 IU/lt; baseline value: $68 \mathrm{IU} / \mathrm{lt}$ ), which necessitated serologic tests. Serologic tests for Human Immunodeficiency Virus (HIV) and Hepatitis C Virus (HCV) were negative, but Hepatitis B Surface Antigen (HBsAg) positivity was reported. Department of Infectious Diseases was consulted. Slight elevations in hepatic enzymes and absence of active infection or replication reportedly indicated that the patient had not an active infection, but had a history of AS, or he was a carrier. Pelvic $\mathrm{X}$-ray showed bilateral stage 3 sacroiliitis and established the axial involvement of ankylosing spondylitis. Related AS index scores were as follows: Bath Ankylosing Spondylitis Functional Index (BASFI): 4.55;

*Corresponding author: Beril Dogu, Department of Physical Medicine and Rehabilitation, Sisli Hamidiye Etfal Education and Research Hospital, Istanbul, Turkey, Tel: +90 53262252 84; E-mail: berildogu@hotmail.com

Received October 02, 2013; Accepted November 08, 2013; Published November 16,2013

Citation: Buyukavcı R, Sahin F, Dogu B, Kuran B (2013) A Case with Ankylosing Spondylitis Who Developed Hodgkin Lymphoma Following Etanercept Therapy. J Arthritis 2: 114. doi:10.4172/2167-7921.1000114

Copyright: (c) 2013 Buyukavcı R, et al. This is an open-access article distributed under the terms of the Creative Commons Attribution License, which permits unrestricted use, distribution, and reproduction in any medium, provided the original author and source are credited. 
Bath Ankylosing Spondylitis Disease Activity Index (BASDAI): 5.05; Bath Ankylosing Spondylitis Metrology Index (BASMI): 3. Quality of life Short Form (SF-36) was evaluated with general quality of life scores. Physical function subgroup score was 41 (range 0-100). Visual Analogue Scale (VAS) and nocturnal and total pain score were 50 and 98, respectively. Treatment was initiated with diclofenac sodium $(150 \mathrm{mg} /$ daily) and switched to indomethacine, when no benefit was observed with respect to pain $(150 \mathrm{mg} /$ daily).

During the follow-up period, low back pain of the patient intensified. He did not respond to ASAS 20 or subsequent indomethacin. A high ESR level of $47 \mathrm{~mm} / \mathrm{h}$ and a CRP level of $25 \mathrm{mg} / \mathrm{l}$ prompted us to plan etanercept treatment $(2 \times 25 \mathrm{mg} / \mathrm{w} \mathrm{sc})$. Essential tests before initiating anti-TNF therapy were performed. Hematological and biochemical tests were within normal limits. At control visit 2 months later, hematological tests were within normal range, ESR was $9 \mathrm{~mm} / \mathrm{h}$, and CRP was $8.4 \mathrm{mg} / \mathrm{l}$. The patient described a decrease in pain severity. A satisfactory ASAS-20 response was achieved.

Three months later, the patient was seen again. He was admitted to surgery for palpable swellings on the right inguinal and hypochondrial region persisting for a month. An abdominal ultrasonographic evaluation revealed an initial diagnosis of mesenteric lymphadenitis. Results of the control hematologic tests necessitated (WBC: 13250/ $\mathrm{mm}^{3}, \mathrm{Hb}: 13 \mathrm{~g} / \mathrm{dl}$, Hct: 42\%, PLT: $393000 \mathrm{~mm}^{3}$, CRP: 17,1 mg/l) discontinuation of etanercept therapy and consultations from Department of Surgery and Internal Diseases were requested in order to determine the etiologic status of lymph nodes. Biopsy specimens were sampled from lymphadenopathies at an outside center and ultimately the patient was diagnosed with lymphoma, for which chemotherapy was initiated.

\section{Discussion}

ASAS study group introduced a number of criteria for administration of anti-TNF therapy in patients with established diagnosis of AS according to Modified New York criteria. These criteria are as follows: BASDAI score of (0-100), physician's conviction in the necessity of this therapy, patient's belief that it is beneficial for him/her, failure of the standard treatment performed, and lack of any related contraindication [3]. In our patient, we switched to anti-TNF therapy after unsatisfactory response to the treatment with 2 different full dose NSAIDs for 3 months, progression of the axial disease, and absence of any contraindication.

Etanercept is a TNF- $\alpha$ antagonist which has received FDA approval for the treatment of AS. In 124 patients with AS, Chan-Bum et al. [7] evaluated safety of the drug in terms of side effects and the response to treatment according to ASAS 20 response criteria after 3 months of etanercept usage. ASAS 20 response was achieved in $79.8 \%$ of the patients and no side effects were reported in any patient. Davis et al. [8] did not report any side effect or serious adverse effect in 277 AS patients treated with etanercept for 192 weeks.

Many studies have been conducted so far to study the risk of malignancy in connective tissue disorders, especially in RA. An increased lymphoma risk has been demonstrated in RA. However, only few studies have investigated malignancy risk in spondylarthroses, especially AS. In a Swedish case-control study, Askling et al. [9] reported no increased lymphoma risk in patients with AS when anti-TNF drugs were not used. There are recent reports suggesting an increased rate of both Hodgkin and non-Hodgkin lymphoma in AS patients using anti-TNF drugs. These reports advocated that concurrence of AS and lymphoma is not a coincidence, but it may rather be a complication of etanercept therapy $[10,11]$. In our case, HL emerged at nearly $12^{\text {th }}$ week of etanercept treatment. Brown et al. reported that lymphoma developed approximately at the $8^{\text {th }}$ week of the therapy when etanercept was used in inflammatory rheumatic disease (15 RA, 2 PSA and one undefined) in 18 patients. Among them, 13 patients were using methotrexate before or simultaneously with etanercept therapy and 16 of them had NHL [12].

Some studies have examined the relationship between HL, NHL and Hepatitis B Virus (HBV). Hepatotropic HBV has a proliferative potential in lymphoid cells. The pathogenesis of lymphoma associated with viral agents is an extremely complex process involving significant biologic and clonal genetic variations in host and target cells. Certain reports have pointed at the role of $\mathrm{HCV}$ in the pathogenesis of NHL $[13,14]$. Similar to HCV, HBV is both a hepatotropic and lymphotropic virus. Although there are many studies investigating the possible role of $\mathrm{HCV}$ in the pathogenesis of $\mathrm{HCV}$, studies examining the pathogenetic associations between HBV, NHL and HL are extremely rare [15]. Some recent studies have reported a higher incidence of HbsAg positivity. Given the lymphotropic characteristics of HBV, potential role of HBV in the pathogenesis of lymphoma as in hepatocarcinogenesis have begun to attract attention. There was also HbsAg positivity in our patient. Although some reports have considered HBV infection as a relative contraindication for anti-TNF drugs, they have not mentioned carrying any disease or previously contracted infections.

In a similar case to ours, Aksu et al. [10] reported another case from our country who developed HL after short term etanercept usage for ankylosing spondylitis. They emphasized that it should not be forgotten that anti-TNF drug therapies may induce the development of lymphomas not only in RA, but also in AS.

Similar to the literature data, anti-TNF use in our patient may have led to susceptibility for lymphoma. As a conclusion, although the risk of lymphoma associated with etanercept use has not been established yet, this risk should not be disregarded especially in patients with spondyloarthritis who are treated with TNF- $\alpha$ antagonist.

\section{References}

1. van der Linden S, van der Hijde D, Braun J (2005) Ankylosing spondylitis I: Harris EJ, Budd R, Firestein GS, Genovese MC, Sergent JS, Sledge CB, editors. Kelley's text book of rheumatology. (7thedn). Philapelpdia Elsevier Saunders: 1125-1141.

2. Özgül A, Peker F, Taşkaynatan MA, Tan AK, Dinçer K, et al. (2006) Effect of Ankylosing spondylitison health-related quality of life and different aspects of social life in young patients. Clin Rheumatol 25: 168-174.

3. Braun J, Pham T, Sieper J, Davis J, van der Linden S, et al. (2003) Internationa ASAS consensus statement for the use of anti-tumour necrosis factor agents in patients with ankylosing spondylitis. Ann Rheum Dis 62: 817-824.

4. Gorman JD, Sack KE, Davis JC (2002) Treatment of ankylosing spondylitis by inhibition of tumor necrosis factor alpha. N Engl J Med 346: 1349-1356.

5. Calin A, Dijkmans BA, Emery P, Hakala M, Kalden J, et al. (2004) Outcomes of a multicentre randomised clinical trial of etanercept to treat ankylosing spondylitis. Ann Rheum Dis 63: 1594-1600.

6. Bernatsky S, Ramsey-Goldman R, Clarke A (2006) Malignancy and autoimmunity. Curr Opin Rheumatol 8: 129-134.

7. Chan-Bum C, Tae-Jong K, Hee-Jin P, Wan-Sik U, Jae-Bum J, et al. (2008) Safety and Clinical Responses in Ankylosing Spondylitis after ThreeMonths of Etanercept Therapy. J Korean Med Sci 23: 852-856.

8. Davis JC Jr, van der Heijde DM, Braun J, Dougados M, Clegg DO, et al. (2008) Efficacy and safety of up to 192 weeks of etanercept therapy in patients with ankylosing spondylitis. Annals of the Rheumatic Diseases 67: 346-352. 
Citation: Buyukavcı R, Sahin F, Dogu B, Kuran B (2013) A Case with Ankylosing Spondylitis Who Developed Hodgkin Lymphoma Following Etanercept Therapy. J Arthritis 2: 114. doi:10.4172/2167-7921.1000114

Page 3 of 3

9. Askling J, Klareskog L, Blomqvist P, Fored M, Feltelius N (2006) Risk for malignant lymphoma in ankylosing spondylitis: a nationwide Swedish casecontrol study. Ann Rheum Dis 65: 1184-1187.

10. Aksu K, Dönmez A, Ertan Y, Keser G, Inal V, et al. (2007) Hodgkin's lymphoma following treatment with etanercept in ankylosing spondylitis. Rheumatol Int 28 : 185-187.

11. Aksu K, Cagirgan S, Ozsan N, Keser G, Sahin F (2011) Non-Hodgkin's lymphoma following treatment with etanercept in ankylosing spondylitis. Rheumatology Int 31; 1645-1647.

12. Brown SL, Greene MH, Gershon SK, Edwards ET, Braun MM (2002) Tumor necrosis factor antagonist therapy and lymphoma development: twenty-six cases reported to the Food and Drug Administration. Arthritis Rheum 46: 31513158.

13. Negri E, Little D, Boiocchi M, La Vecchia C, Franceschi S (2004) B-cell nonHodgkin's lymphomas and hepatitis $C$ virus infection: A systematic review. Int J Cancer 111: 1-8.

14. Ahmed N, Heslop HE (2006) Viral lymphomagenesis. Curr Opin Hematol 13 254-259.

15. Marcucci F, Mele A, Spada E, Candido A, Bianco E, et al. (2006) High prevalence of hepatitis B virus infection in B-cell non- Hodgkin lymphoma Haematologica 91: 554- 557. 